\title{
Comparison of OMI ozone and UV irradiance data with ground-based measurements at two French sites
}

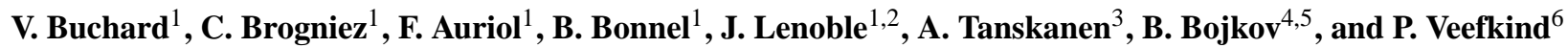 \\ ${ }^{1}$ Laboratoire d'Optique Atmosphérique, Université des Sciences et Technologies de Lille, France \\ ${ }^{2}$ Interaction Rayonnement Solaire Atmosphère, Université Joseph Fourier de Grenoble, France \\ ${ }^{3}$ Finnish Meteorological Institute, Helsinki, Finland \\ ${ }^{4}$ Goddard Earth Sciences and Technology Center, University of Maryland, Baltimore County, Baltimore, Maryland, USA \\ ${ }^{5}$ Atmospheric Chemistry Dynamics Branch, NASA Goddard Space Flight Center, Greenbelt, Maryland, USA \\ ${ }^{6}$ Royal Netherlands Meteorological Institute, De Bilt, The Netherlands
}

Received: 18 January 2008 - Published in Atmos. Chem. Phys. Discuss.: 3 March 2008

Revised: 2 July 2008 - Accepted: 8 July 2008 - Published: 5 August 2008

\begin{abstract}
Ozone Monitoring Instrument (OMI), launched in July 2004, is dedicated to the monitoring of the Earth's ozone, air quality and climate. OMI is the successor of the Total Ozone Mapping Spectrometer (TOMS) instruments and provides among other atmospheric and radiometric quantities the total column of ozone (TOC), the surface ultraviolet (UV) irradiance at several wavelengths, the erythemal dose rates and the erythemal daily doses. The main objective of this work is to compare OMI data with data from ground-based instruments in order to use OMI products (collection 2) for scientific studies. The Laboratoire d'Optique Atmosphérique (LOA) located in Villeneuve d'Ascq (VdA) in the north of France performs solar UV measurements using a spectroradiometer. The site of Briançon in the French Southern Alps is also equipped with a spectroradiometer operated by Interaction Rayonnement Solaire Atmosphère (IRSA). The OMI total ozone column data is obtained from the OMI-TOMS and OMI-DOAS algorithms. The comparison between the TOC retrieved with ground-based measurements and OMI-TOMS data shows good agreement at both sites for all sky conditions with a relative difference for most of points better than 5\%. For OMI-DOAS data, the agreement is generally better than $7 \%$ and these data show a significant dependence on solar zenith angle. Comparisons of spectral UV on clear sky conditions are also satisfying with relative differences smaller than $10 \%$ except at solar zenith angles larger than $65^{\circ}$. On the contrary, results of compar-
\end{abstract}

Correspondence to: V. Buchard (buchard@loa.univ-lille1.fr) isons of the erythemal dose rates and erythemal daily doses for clear sky show that OMI overestimates surface UV doses at VdA by about $15 \%$ and that on cloudy skies, the bias increases. At Briançon, such a bias is observed if data corresponding to snow-covered surface are excluded.

\section{Introduction}

The solar UV radiation has a large impact on human life, animals and plants, with both positive and negative effects. For example, exposure to solar UV enables the synthesis of vitamin D in skin whereas skin cancer or eye diseases can be caused by excessive doses of UV radiation (WMO, 2007). Atmospheric ozone is one of the main factors affecting the surface UV radiation, so its decline observed at middle and high latitudes since the 1980s has led to monitoring of atmospheric ozone content and UV radiation. Ground-based instruments devoted to this monitoring have been developed in many countries as well as satellite instruments which allow a global geographical coverage.

Satellite data are affected by instrumental errors, as data from ground-based instruments (Bernhard and Seckmeyer, 1999), but are also affected by modelling uncertainties in deriving surface UV irradiance from UV radiance measured at the top of atmosphere. Therefore, satellite derived products need to be validated with ground-based measurements. Previous comparisons between satellite surface UV data provided by TOMS and ground-based measurements have been extensively done (Kalliskota et al., 2000; McKenzie et al, 2001; Cede et al., 2004; Arola et al., 2005; Kazantzidis et al.,

Published by Copernicus Publications on behalf of the European Geosciences Union. 
2006). They concern mainly snow-covered surface, clouds and aerosols effects on the UV irradiance derived from satellite. The TOC inferred from satellite measurements requests also validation. All these validations must be achieved with care because of a scale issue, indeed ground-based measurements are representative only of a small local area whereas satellite measurements are representative of a large region (OMI pixel at nadir $\sim 13 \times 24 \mathrm{~km}^{2}$ ) so that difficulties can arise from the cloud or aerosol variability.

The ground-based instruments used to perform spectral irradiance measurements and the OMI instrument are described in Sect. 2 along with the methodologies for inferring the TOC and surface UV from ground-based and from OMI measurements. Section 3 presents comparisons between the OMI products and the products retrieved at two French sites, Villeneuve d'Ascq $\left(50.61^{\circ} \mathrm{N}, 3.14^{\circ} \mathrm{E}, 70 \mathrm{~m}\right.$ a.s.1.) and Briançon $\left(44.90^{\circ} \mathrm{N}, 6.65^{\circ} \mathrm{E}, 1330 \mathrm{~m}\right.$ a.s.1.). Section 4 reports the conclusions.

\section{Instruments and methodologies}

\subsection{Ground-based instruments}

Measurements of the instruments located at Villeneuve d'Ascq and Briançon are used in this study. These sites are typical respectively of a flat region in the north of France and a high altitude valley of the French Southern Alps.

The spectroradiometers at $\mathrm{VdA}$ and Briançon are thermally regulated Jobin Yvon H10 double monochromators, and they scan the wavelength range from 280 to $450 \mathrm{~nm}$ with a sampling step of $0.5 \mathrm{~nm}$. Their spectral resolution is about $0.7 \mathrm{~nm}$ (Full Width at Half Maximum, FWHM). Calibration is performed every 3 months with two standard lamps traceable to NIST (National Institute of Standards and Technology) and NPL (National Physical Laboratory), leading to an irradiance expanded uncertainty (coverage factor $\mathrm{k}=2$ ) of about $8 \%$ at $300 \mathrm{~nm}$ and about $5 \%$ at $400 \mathrm{~nm}$ for a high irradiance level and $10 \%$ and $7 \%$ respectively for a low irradiance level. The instrument has been checked within the QASUME (Quality Assurance of Spectral Ultraviolet Measurements in Europe) project in September 2004 (Gröbner et al., 2006). The spectroradiometers perform scans of the global irradiance from sunrise to sunset every $30 \mathrm{~min}$. A single spectral scan takes about 6 min.

The broadband instrument in VdA is a UVB-1 type from Yankee Environmental System (YES), it delivers measurements of erythemal dose rate with a three minutes time frequency. It was calibrated in August 2006 during COST-726 campaign.

\subsubsection{Ozone retrieval}

The total ozone column is routinely retrieved from the ground-based global irradiance spectrum using a differential absorption technique (Stamnes et al., 1991). This method is based on the comparison between two ratios of irradiances at two selected wavelengths (one where the ozone absorption is strong and the other where it is weak). One ratio is simulated beforehand and is stored in a look up table (LUT) and the other is calculated from the UV measurements (Houët and Brogniez, 2004). The LUTs are built using a Radiative Transfer Code (DISORT, DIScret Ordinates Radiative Transfert, Stamnes et al., 1988) for various solar zenith angles and total ozone columns. The ozone absorption cross-sections used to calculate the LUT are taken from Paur and Bass at $221 \mathrm{~K}$ (1985). With this technique, it is possible to retrieve ozone under clear sky and cloudy conditions. A previous study (Brogniez et al., 2005) has shown that under cloudy conditions the daily ozone mean is a rather good estimation of the true value. The uncertainties on the ozone retrieval are about $3 \%$ on clear sky and on cloudy days, the performance depends on the cloudiness: for example for cloudiness lower than 4 octas, the averaged uncertainty is about $4 \%$, when cloudiness is larger than 4 octas, the averaged uncertainty is about $7 \%$. So, in this study daily averages of the ground-based data obtained for all sky conditions and for zenith angles smaller than $75^{\circ}$ are compared with OMI values obtained during overpass. Other comparisons with averaged ground-based values close to the satellite overpass time are also conducted.

\subsubsection{UV irradiance}

Erythemal dose rates are computed from ground-based spectra using CIE action spectrum (Diffey and McKinlay, 1987) and erythemal daily doses are computed integrating the erythemal dose rates over the day.

To carry out comparison of two spectra measured by two instruments with slit functions of different FWHM one has to process the spectra to set them at a common FWHM (Slaper et al., 1995; Bais et al., 2001). Therefore, the ground-based spectra were first deconvolved using their own FWHM and then reconvolved with a triangular slit function with FWHM of $0.55 \mathrm{~nm}$ in order to make the spectroradiometer irradiance comparable to the spectral irradiances produced by the OMI surface UV algorithm. The processing was carried out using the SHICrivm tool (Slaper et al., 1995).

\subsection{Ozone monitoring instrument}

OMI is a Dutch/Finnish instrument onboard the NASA Earth Observing System (EOS) Aura spacecraft (Levelt et al., 2006a). OMI is a nadir-viewing UV/Visible spectrometer with a spectral resolution about $0.63 \mathrm{~nm}$ for the visible channel $(349-504 \mathrm{~nm})$ and about $0.42 \mathrm{~nm}$ for the UV channel $(307-383 \mathrm{~nm})$. It measures the solar light scattered by the atmosphere in the $270-500 \mathrm{~nm}$ wavelength range with a spatial resolution at nadir of $13 \mathrm{~km} \times 24 \mathrm{~km}$. The sun-synchronous orbit of Aura and the wide viewing angle of OMI enable daily global coverage of the sunlit portion of the Earth. OMI is 
the successor of TOMS instruments and contributes to monitoring of the atmospheric ozone, trace gases, aerosols and surface UV radiation (Levelt et al., 2006b).

\subsubsection{OMI total column ozone data}

Two algorithms are used to derive the total column of ozone from OMI measurements. One of the two algorithms is the TOMS Version 8 algorithm (Bhartia et al., 2002). The same algorithm was used to reprocess all the TOMS data since 1978. It uses two wavelengths to derive total ozone, 317.5 and $331.2 \mathrm{~nm}$ under most conditions, 331.2 and $360 \mathrm{~nm}$ for high ozone and high solar zenith angle and also other wavelengths for quality control.

The relative uncertainty on this OMI-TOMS-like product is around $2 \%$ for solar zenith angle lower than $70^{\circ}$ and increasing to $5 \%$ at $85^{\circ}$ according to Bhartia et al. (2002).

The other algorithm developed by KNMI (Koninklijk Nederlands Meteorologisch Instituut in the Netherlands) is based on the Differential Optical Absorption Spectroscopy (DOAS) technique. In the DOAS algorithm, the TOC is determined in three steps. In the first step, to obtain the socalled slant column density (the amount of ozone along an average photon path from the Sun to the satellite), the actual DOAS fitting is performed. In the second step, the air mass factor is determined, which is needed to convert the slant column density into a vertical column. The third step consists of a correction for cloud effects. According to Veefkind et al. (2006), the relative uncertainty on this OMI-DOAS-like product is about $3 \%$ for cloudy days and $2 \%$ for clear days.

\subsubsection{OMI surface UV data}

The algorithm used to estimate the UV radiation reaching the Earth's surface is similar to the algorithm used to retrieve UV from the TOMS data (Herman et al., 1999; Krotkov et al., 2002). This OMI surface UV algorithm is based on the use of a radiative transfer model using the OMI-derived total ozone and cloud information as input parameters for modelling. The surface albedo data are obtained from a climatology based on the Nimbus-7/TOMS measurements (Tanskanen, 2004). First of all, the clear-sky surface irradiance is calculated and then a correction is made taking into account the attenuation of the UV radiation by clouds and scattering aerosols (Tanskanen et al., 2006). The speed of the algorithm is optimized using precalculated lookup tables. The OMI surface UV algorithm produces estimates of erythemal daily dose as well as local solar noon erythemal irradiance and spectral irradiances at 305.1, 310.1, 324.1 and $380.1 \mathrm{~nm}$ which are calculated using a triangular slit function whose FWHM is $0.55 \mathrm{~nm}$. For validation purposes a modified version of the OMI surface UV algorithm was used to produce for VdA a time series of OMI-derived erythemal dose rates and spectral irradiances corresponding to the OMI overpass

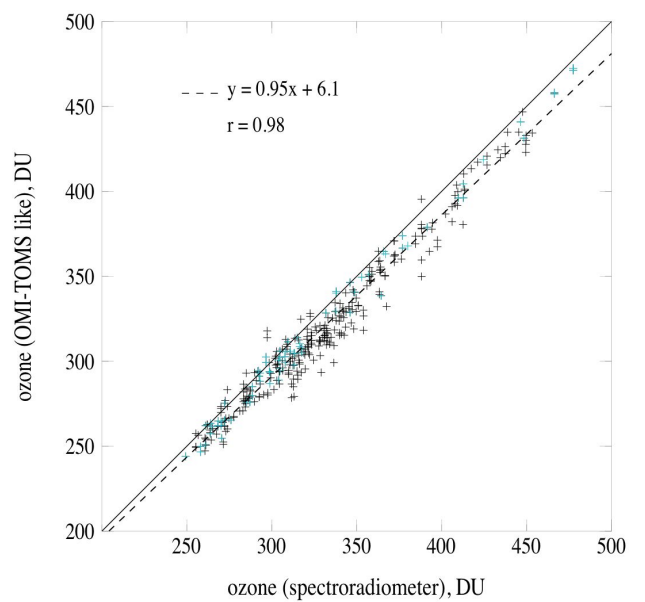

Fig. 1a. Comparison between TOC from the ground-based instrument in Briançon and from OMI-TOMS-like method for all sky conditions (blue cross represents snowy surface days). The equation of the regression line (dash line) and the correlation coefficient are indicated, the solid line is the first bisector.

time. In the future these additional products will be added to the standard OMUVB product.

The accuracy of the OMI-derived daily doses was assessed in a recent validation study (Tanskanen et al., 2007). According to the validation results the OMI-derived daily erythemal doses have a median overestimation of $0-10 \%$ for flat, snow-free regions with modest loadings of absorbing aerosols or trace gases, and some 60 to $80 \%$ of the doses are within $\pm 20 \%$ from the ground reference. For sites significantly affected by absorbing aerosols or trace gases the positive bias can be up to $50 \%$. Because the aerosol absorption cross sections tend to increase as the wavelength decreases, even bigger biases are expected for the low wavelength spectral irradiances derived from the OMI measurements. Thus, comparison of the OMI-derived spectral irradiances with the ground-based measurements will contribute to understanding of the effect of aerosols on surface UV as well as further development of the OMI surface UV algorithm.

\section{Results}

\subsection{Ozone comparisons}

We present scatter plots of the TOC derived from the groundbased instrument at both sites and from OMI derived with the two techniques and also time series of the relative differences (OMI-GB)/GB in percent, where GB represents the TOC from the ground-based instrument. As stated in Sect. 2.1.1, the ground-based data are daily averages.

Figure 1a shows the comparison between the TOC retrieved in Briançon and the TOC OMI-TOMS-like, for the period October 2004-September 2005 considering all sky 


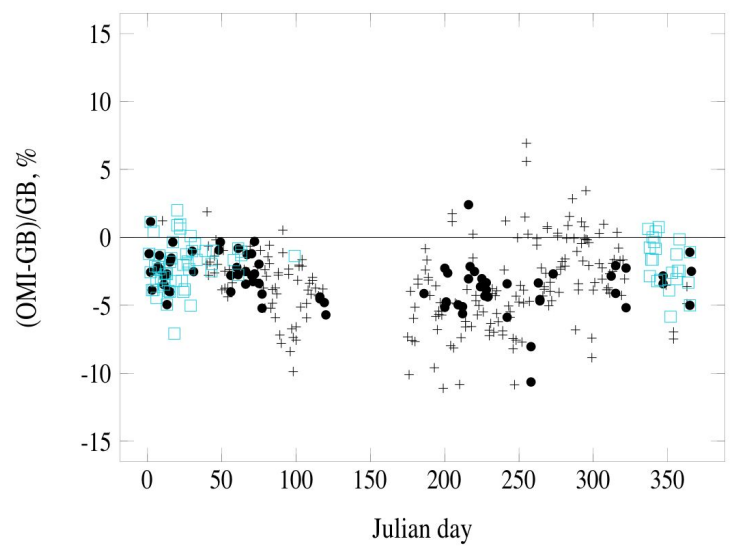

Fig. 1b. Time series of the relative differences between groundbased and OMI-TOMS-like TOC in Briançon (cross represent cloudy day data, black dots represent clear days and blue squares represent snowy surface days, black dots inside blue squares are for clear snowy days).

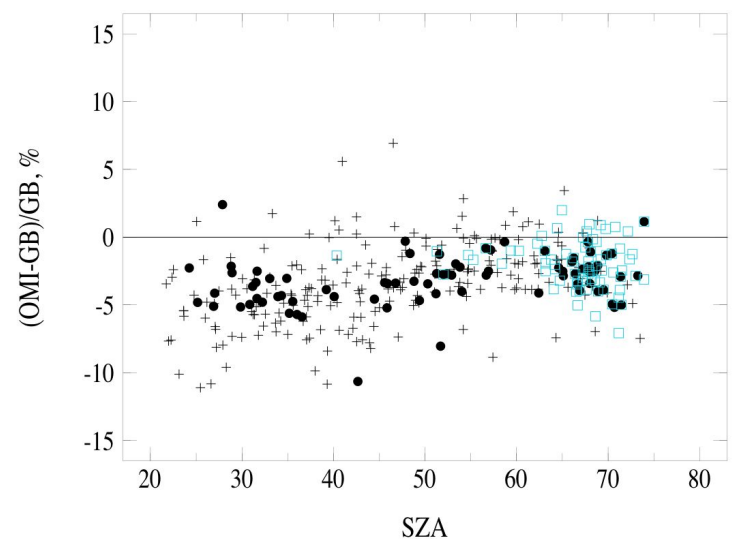

Fig. 1c. Relative differences between ground-based and OMITOMS-like TOC in Briançon versus SZA (cross represent cloudy day data, black dots represent clear sky days and blue squares represent snowy surface days, black dots inside a blue squares for clear snowy days).

conditions. (The comparison with the TOC OMI-DOAS-like is not presented for Briançon since the data are not available for the previous period).

Figure $1 \mathrm{~b}$ presents the time series of the relative differences, with cloudy sky data plotted as cross, clear sky data as black points and with the snow-covered surface data as blue squares.

Accounting for the uncertainties on both products, the comparison is rather satisfying but we note a negative bias (TOC spectroradiometer $>$ TOC OMI) about $-3.1 \%$, with discrepancies more important in summer. This seasonal effect can be explained by a cloud effect since clear sky data (black dots) show no seasonal variation. In this study, the days with snow-covered ground (blue squares) show no par-

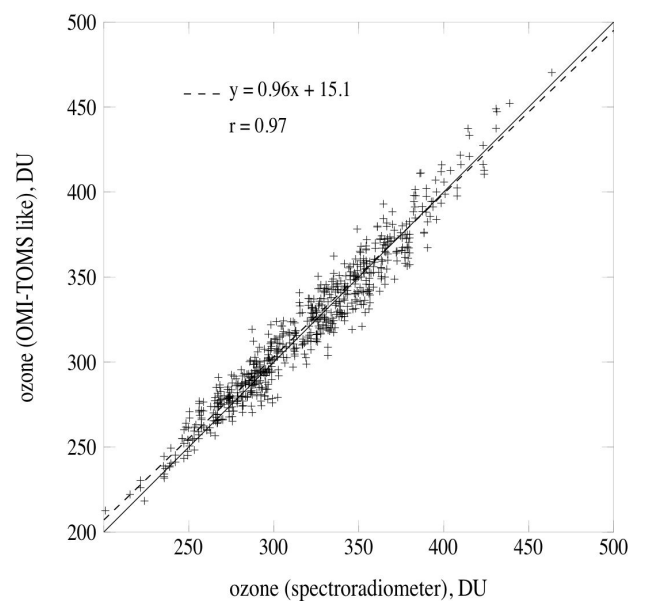

Fig. 2a. Same as Fig. 1a for OMI-TOMS-like method but in VdA.

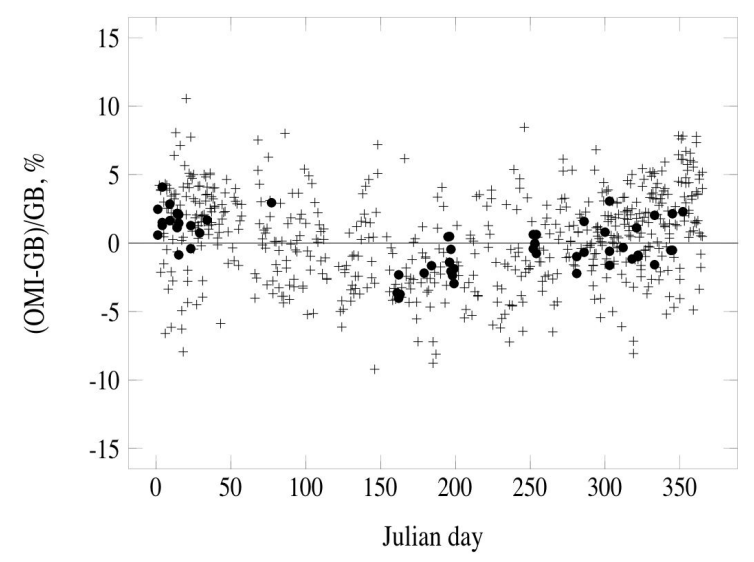

Fig. 2b. Same as Fig. 1b for OMI-TOMS-like method but in VdA.

ticular effect. If we consider only the clear days, the comparison is slightly better, the equation of the regression line is $y=0.99 \times-7.1$ with a correlation coefficient equal to 0.99 .

When looking at relative differences versus the solar zenith angle (SZA) corresponding to OMI data (Fig. 1c), the largest discrepancies observed in summer (smallest SZA) are confirmed for cloudy sky condition data. For clear sky the dependency is small.

Figure $2 \mathrm{a}-\mathrm{c}$ present the results for the site of $\mathrm{VdA}$ for OMI-TOMS-like method for the period October 2005February 2007.

The scatter plot in Fig. 2a shows similar results as in Fig. 1a.

In Fig. 2b no obvious seasonal effect appears for cloudy days (cross) but in case of clear sky (black dots), the seasonal effect appears unambiguously, OMI TOC is smaller than GB TOC in summer while it is generally the reverse (or no difference) during the rest of the year. If we look at Fig. 2c, we notice that, for the majority of points with large SZA for all sky conditions, OMI TOC is greater than GB TOC. 


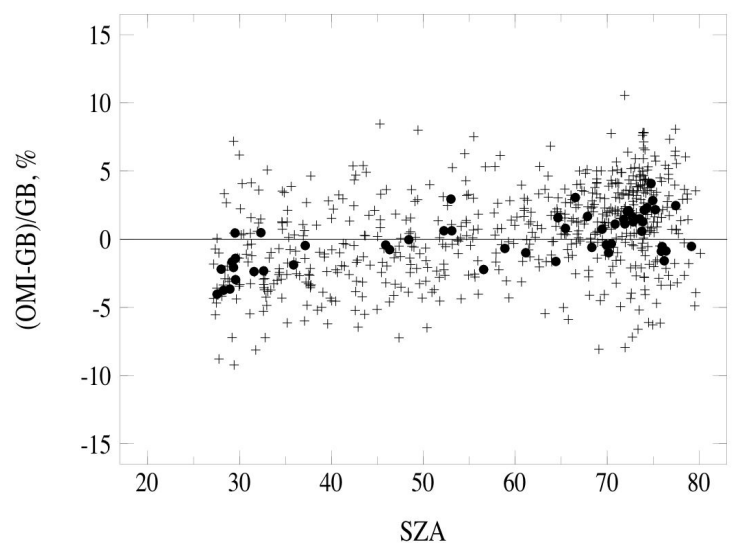

Fig. 2c. Same as Fig. 1c for OMI-TOMS-like method but in VdA.

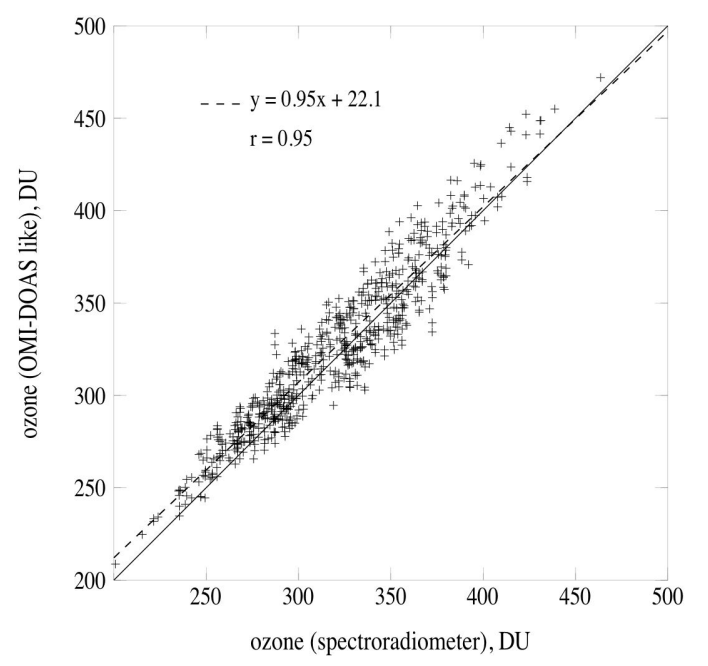

Fig. 2d. Same as Fig. 2a but for TOC from OMI-DOAS-like method.

For the comparison on clear sky days, the relative differences do not exceed 5\%, the correlation coefficient is 0.98 and the equation of the regression line is $y=0.98 x+7.6$ much satisfying that for all sky conditions.

Figure $2 \mathrm{~d}-\mathrm{f}$ present the results for the site of $\mathrm{VdA}$ for OMI-DOAS-like method for the same period as previously.

Considering the Fig. 2e and f, obviously there is a seasonal effect for both clear and cloudy sky condition data. Dependence with SZA is very important even by clear sky. Balis et al. (2007) found also a significant dependence on SZA between OMI-DOAS and ground-based data at several sites.

The regression line for only clear sky data is $y=0.99 x+6.3$ much better than for all sky conditions with a correlation coefficient equal to 0.96 . The agreement is better particularly in summer, with relative differences lower than $5 \%$.

Other comparisons with averages of ground-based values close to the satellite overpass time show similar results (not shown).

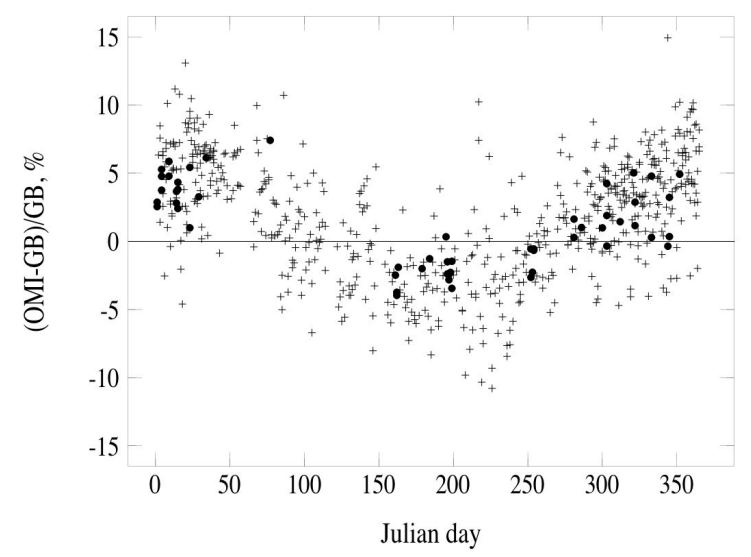

Fig. 2e. Same as Fig. $2 b$ but for TOC from OMI-DOAS-like method.

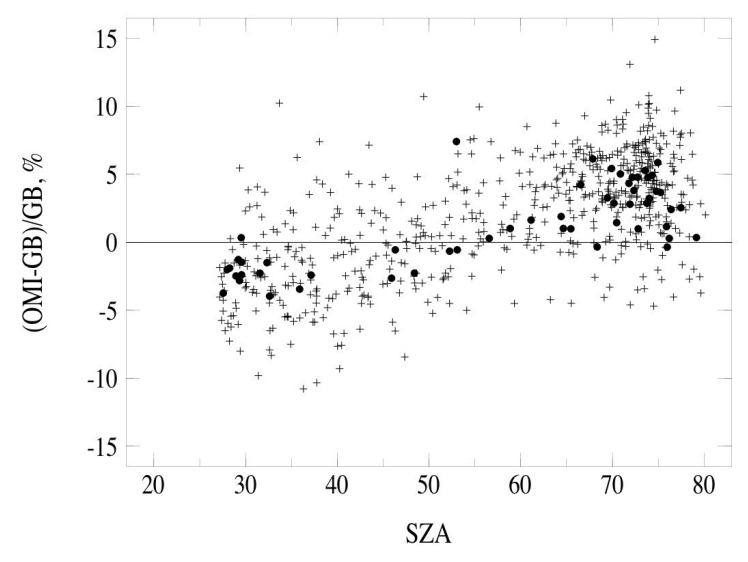

Fig. 2f. Same as Fig. 2c but for TOC from OMI-DOAS-like method.

To summarize, in VdA we have a better agreement between the ground-based TOC and OMI-TOMS-like TOC (the RMS (root mean square of the relative differences) is equal to $3.2 \%$ and the average of the relative differences is equal to $0.5 \%$ ) than with the DOAS method (RMS $=4.7 \%$, average of the relative differences $=1.9 \%$ ) and there is a strong SZA effect.

\subsection{Surface UV comparisons}

\subsubsection{Spectral UV}

OMI spectral irradiances are available in VdA at the time of overpass. Figure 3 a shows the comparison with the spectroradiometer at wavelength $324.1 \mathrm{~nm}$ and Fig. $3 \mathrm{~b}$ shows the comparison at wavelength $380.1 \mathrm{~nm}$ for the period October 2005-February 2007 only for clear sky conditions. The correlations are excellent at both wavelengths but we observe that there is a bias at $324.1 \mathrm{~nm}$ and that the regression line is worse at $380.1 \mathrm{~nm}$. 


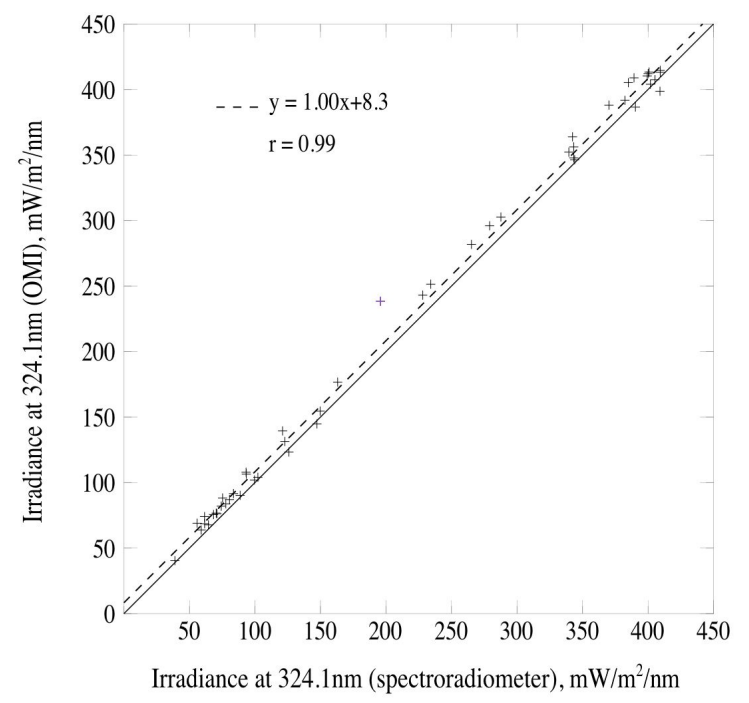

Fig. 3a. Comparison between spectral irradiance at $324.1 \mathrm{~nm}$ from the spectroradiometer in $\mathrm{VdA}$ and from OMI at the time of overpass for clear skies (the violet cross is studied later).

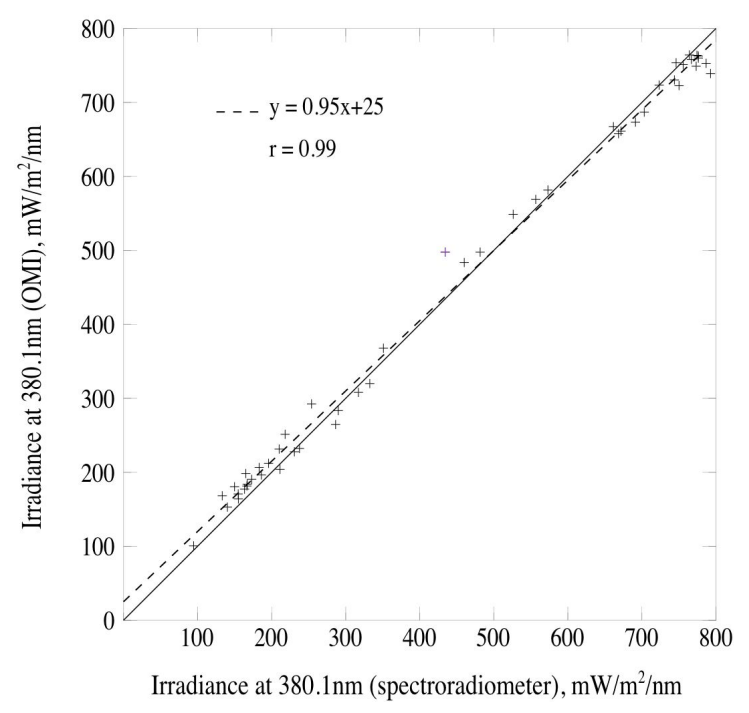

Fig. 3b. Same as Fig. 3a but at $380.1 \mathrm{~nm}$.

The relative difference is plotted versus the spectral irradiance measured by the spectroradiometer in Fig. 3c $(324.1 \mathrm{~nm})$ and in Fig. $3 \mathrm{~d}(380.1 \mathrm{~nm})$. The bias observed in Fig. $3 \mathrm{a}$ for $324.1 \mathrm{~nm}$ appears clearly, it is about $6.5 \%$; moreover we can note at both wavelengths larger differences up to $25 \%$ for low irradiances.

If we look at the plot of the relative differences versus SZA (Fig. 3e), we see larger discrepancies for SZA $>65^{\circ}$ at both wavelengths with $\mathrm{OMI}>\mathrm{GB}$ in most cases. For these SZA, the irradiance is low and the uncertainty on the measurements with the ground-based spectroradiometer is larger than at smaller SZA. Only one measurement obtained for $\mathrm{SZA}=53^{\circ}$ gives differences larger than the average values at both wavelengths (violet cross and circle).

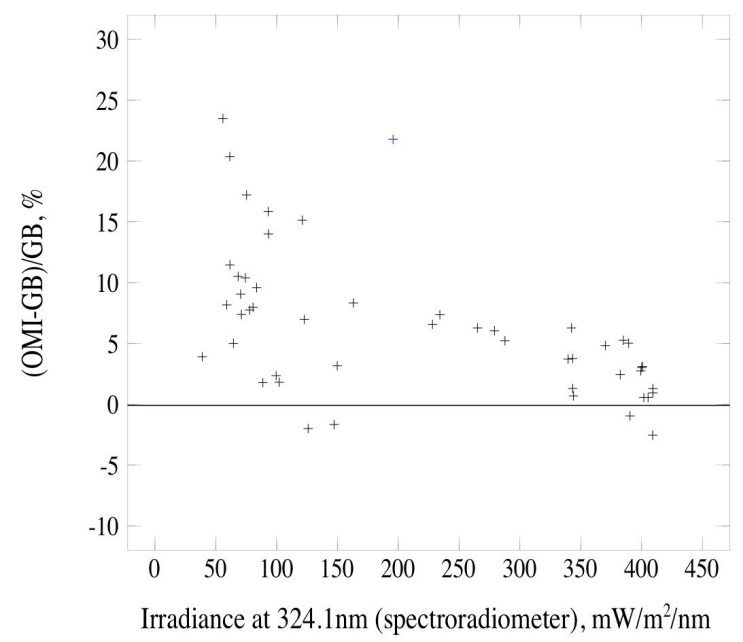

Fig. 3c. Relative differences between ground-based and OMI spectral irradiances at $324.1 \mathrm{~nm}$ as a function of the spectroradiometer irradiance in VdA for clear skies.

Under clear sky conditions, the aerosol optical thickness (AOT) is routinely retrieved from the spectroradiometer measurements (Brogniez et al., submitted, same issue), the lower wavelength at which AOT is retrieved with confidence is $330 \mathrm{~nm}$. Figure $3 \mathrm{f}$ and $\mathrm{g}$ shows that there exists a weak correlation between the differences and the AOT for most days (the correlation coefficient is about 0.6), larger relative differences correspond to larger AOT. Arola et al. (2005) have also studied for TOMS the correlation between UV irradiance differences at $324 \mathrm{~nm}$ and absorption AOT, they found a better correlation (about 0.8). Kazantzidis et al. (2006) made the same studies but with AOT and found a correlation greater than 0.65. But larger differences at larger SZA seen on Fig. 3e are not systematically explained by large aerosol contents (the AOT for these days are small). Concerning the violet cross for $324.1 \mathrm{~nm}$ in Fig. $3 \mathrm{e}\left(\mathrm{SZA}=53^{\circ}\right)$, the large relative difference $(23 \%)$ can be explained by the large AOT (0.47, violet plus in Fig. 3f). Similarly for $380.1 \mathrm{~nm}$, the large relative difference (15\%) (violet circle in Fig. 3e) is explained by the large AOT (0.47, violet plus in Fig. $3 g$ ).

\subsubsection{Erythemal dose rate}

OMI-derived erythemal dose rates (EDR) are also available for VdA at the time of overpass. Figure $4 \mathrm{a}$ and $\mathrm{b}$ shows the comparison with the spectroradiometer and the radiometer for the period October 2005-February 2007 for all sky conditions. OMI surface UV algorithm overestimates the dose rate by about $33 \%$ on average for the spectroradiometer and about $69 \%$ on average for the radiometer. These values can be explained by the large relative differences at low levels. If we remove the low EDR values, for example lower than $20 \mathrm{~mW} / \mathrm{m} 2$, we get $22 \%$ and $34 \%$ (with about half of the points) respectively. 


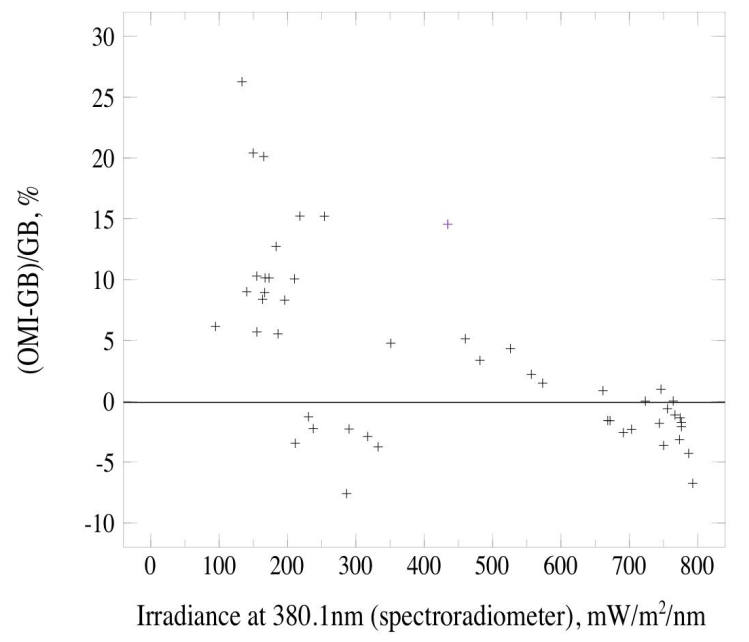

Fig. 3d. Same as Fig. 3c for $380.1 \mathrm{~nm}$.

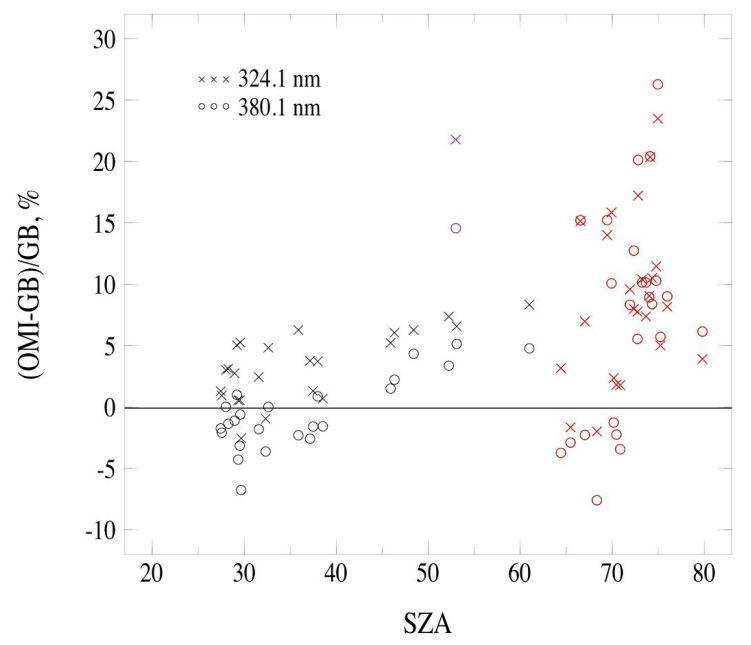

Fig. 3e. Relative differences between ground-based and OMI spectral irradiances for both wavelengths as a function of SZA in VdA for clear skies (red cross and circle for $\mathrm{SZA}>65^{\circ}$ ).

The relative differences (OMI-GB)/GB studied versus the cloud optical depth at $360 \mathrm{~nm}$ (COD) that is derived by the OMI surface UV algorithm, show a dependence (Fig. 4c). The difference between OMI and GB is more important for large COD. A similar study of the relative difference versus the distance between the OMI pixel and the VdA site shows no correlation (not shown).

The same comparison conducted on spectroradiometer data for clear skies only (Fig. 4d) exhibits the same behaviour, however the number of pairs is small (54 points). The points are less scattered than for all sky conditions, (the correlation coefficient is equal to 0.99 and the RMS is about $20 \%$ ).

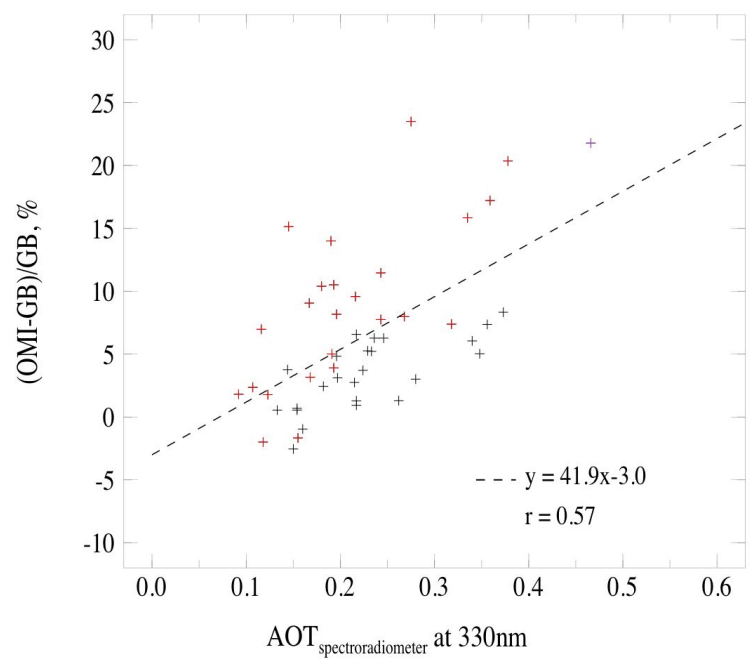

Fig. 3f. Relative differences between ground-based and OMI spectral irradiance at $324.1 \mathrm{~nm}$ as a function of AOT at $330 \mathrm{~nm}$ in VdA for clear skies (red cross for $\mathrm{SZA}>65^{\circ}$ ).

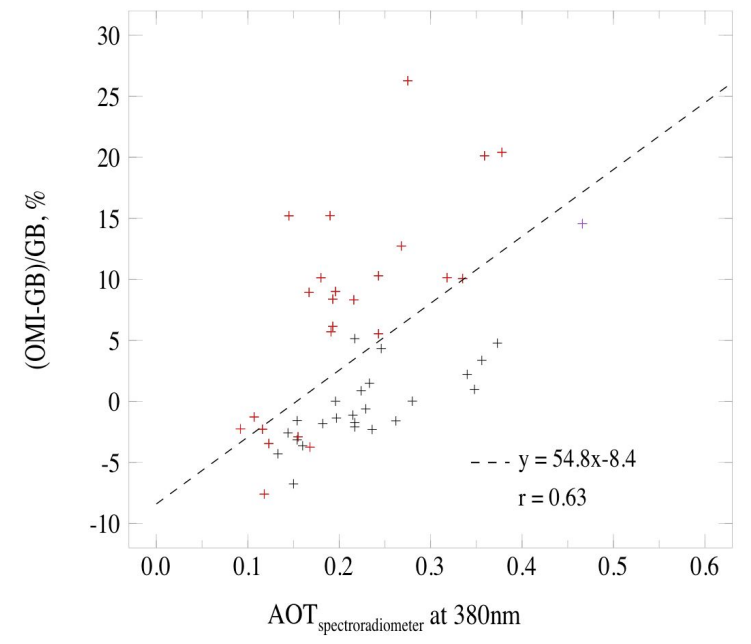

Fig. 3g. Relative differences between ground-based and OMI spectral irradiances at $380.1 \mathrm{~nm}$ as a function of AOT at $380 \mathrm{~nm}$ in VdA for clear skies (red cross for $\mathrm{SZA}>65^{\circ}$ ).

As can be seen in Fig. 4e, a weak correlation $(r=0.60)$ exists between the relative difference and the aerosol content. The bias appears larger at bigger values of AOT. Correlation with the presence of absorbing aerosols is not yet studied since the SSA is not available in the UV range in VdA.

\subsubsection{Erythemal daily dose}

Figure 5a shows the scatter plot of the erythemal daily doses (EDD) derived from OMI and from the spectroradiometer in Briançon for the period October 2004-September 2005 for all sky conditions.

Time series of the relative differences are shown in Fig. 5 b. The data pairs are grouped in three classes: clear-sky, cloudy sky, and snow-covered surface (cloudy or not). 
Table 1. Summary of TOC OMI validation results ( $r$ is the correlation coefficient; $n$ is the number of days included in the comparison; the Root Mean Square:

$\operatorname{RMS}\left(\sqrt{\frac{1}{n} \sum_{i=1}^{n}\left(y_{i}-x_{i}\right)^{2}}\right)$, the $\% \operatorname{RMS}\left(\sqrt{\frac{1}{n} \sum_{i=1}^{n}\left(\frac{y_{i}-x_{i}}{x_{i}}\right)^{2}} \times 100\right)$ and the mean relative difference in $\%\left(\frac{1}{n} \sum_{i=1}^{n}\left(\frac{y_{i}-x_{i}}{x_{i}}\right) \times 100\right)$.

\begin{tabular}{llllrrr}
\hline & $n$ & $r$ & slope & intercept & RMS & $\begin{array}{r}\text { Mean relative } \\
\text { differences }\end{array}$ \\
\hline $\begin{array}{l}\text { Briançon TOC } \\
\text { (OMI TOMS-like) } \\
\text { clear sky Briançon TOC }\end{array}$ & 748 & 0.98 & 0.95 & 6.1 & $13.8 \mathrm{DU}(4.1 \%)$ & $-3.1 \%$ \\
$\begin{array}{l}\text { (OMI TOMS-like) } \\
\begin{array}{l}\text { VdA TOC } \\
\text { (OMI TOMS-like) }\end{array}\end{array}$ & 662 & 0.97 & 0.96 & 15.1 & $10.4 \mathrm{DU}(3.2 \%)$ & $0.5 \%$ \\
$\begin{array}{l}\text { clear sky VdA TOC } \\
\text { (OMI TOMS-like) }\end{array}$ & 56 & 0.98 & 0.98 & 7.6 & $6.2 \mathrm{DU}(1.9 \%)$ & $0.1 \%$ \\
$\begin{array}{l}\text { VdA TOC } \\
\begin{array}{l}\text { (OMI DOAS-like) } \\
\text { clear sky VdA TOC }\end{array}\end{array}$ & 684 & 0.95 & 0.95 & 22.1 & $15 \mathrm{DU}(4.7 \%)$ & $1.9 \%$ \\
\begin{tabular}{l} 
(OMI DOAS-like) \\
\hline
\end{tabular} & 56 & 0.96 & 0.99 & 6.3 & $10.6 \mathrm{DU}(3.3 \%)$ & $1.4 \%$ \\
\hline
\end{tabular}

Table 2. Summary of UV OMI validation results.

\begin{tabular}{|c|c|c|c|c|c|c|}
\hline & $n$ & $r$ & slope & intercept & RMS & $\begin{array}{r}\text { Mean relative } \\
\text { differences }\end{array}$ \\
\hline $\begin{array}{l}\text { VdA EDR OMI }= \\
f(\text { spectroradiometer })\end{array}$ & 723 & 0.96 & 1.08 & 4.4 & $16.5 \mathrm{~mW} / \mathrm{m}^{2}(58 \%)$ & $32.5 \%$ \\
\hline $\begin{array}{l}\text { clear sky VdA EDR OMI= } \\
f(\text { spectroradiometer })\end{array}$ & 54 & 0.99 & 1.14 & 0.5 & $14.7 \mathrm{~mW} / \mathrm{m}^{2}(20 \%)$ & $16.8 \%$ \\
\hline $\begin{array}{l}\text { VdA EDR OMI = } \\
f(\text { radiometer })\end{array}$ & 627 & 0.96 & 1.13 & 6.2 & $17.1 \mathrm{~mW} / \mathrm{m}^{2}(110 \%)$ & $69.3 \%$ \\
\hline $\begin{array}{l}\text { clear sky VdA EDR OMI= } \\
f \text { (radiometer) }\end{array}$ & 45 & 0.99 & 1.14 & 4.2 & $15.1 \mathrm{~mW} / \mathrm{m}^{2}(45 \%)$ & $38.9 \%$ \\
\hline $\begin{array}{l}\text { Briançon EDD OMI= } \\
f(\text { spectroradiometer })\end{array}$ & 293 & 0.97 & 1.22 & -154 & $514 \mathrm{~J} / \mathrm{m}^{2}(24 \%)$ & $7.9 \%$ \\
\hline $\begin{array}{l}\text { VdA EDD OMI= } \\
f(\text { spectroradiometer })\end{array}$ & 349 & 0.99 & 1.14 & 16.6 & $340 \mathrm{~J} / \mathrm{m}^{2}(27.5 \%)$ & $17.1 \%$ \\
\hline $\begin{array}{l}\text { clear sky VdA EDD OMI= } \\
f \text { (spectroradiometer) }\end{array}$ & 33 & 0.99 & 1.13 & 2.3 & $340 \mathrm{~J} / \mathrm{m}^{2}(13.5 \%)$ & $13 \%$ \\
\hline $\begin{array}{l}\text { clear sky VdA Spectral } \\
\text { UV } 324.1 \mathrm{~nm}\end{array}$ & 49 & 0.99 & 1.0 & 8.3 & $12.5 \mathrm{~mW} / \mathrm{m}^{2} / \mathrm{nm}(8.8 \%)$ & $6.4 \%$ \\
\hline $\begin{array}{l}\text { clear sky VdA Spectral } \\
\text { UV } 380.1 \mathrm{~nm}\end{array}$ & 49 & 0.99 & 0.95 & 25 & $21.5 \mathrm{~mW} / \mathrm{m}^{2} / \mathrm{nm}(8.4 \%)$ & $3.7 \%$ \\
\hline
\end{tabular}

It appears that when the ground is covered with snow, the OMI-derived daily dose is generally lower than the ground-based measurement, with large relative difference. The surface albedo used by the OMI surface UV algorithm is a climatological one, and likely it was lower than the actual effective surface albedo at least during the validation campaign. Past studies have also revealed this underestimation of the surface UV provided by TOMS data (Kalliskota et al., 2000; Krotkov et al., 2001, 2002).

If we consider all the data, the average of the relative differences is $8 \%$, but when excluding snowy days, there is a positive difference for the majority of points (generally in summer) and the average of the relative differences is about $14 \%$. 


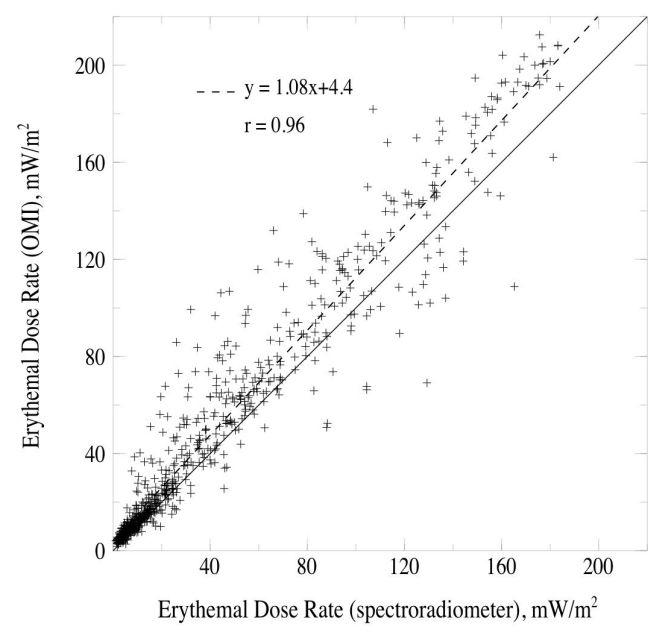

Fig. 4a. Comparison between erythemal dose rate from the spectroradiometer in VdA and erythemal dose rate from OMI at the time of overpass. The equation of the regression line (dash line) and the correlation coefficient are indicated, the solid line is the first bisector.

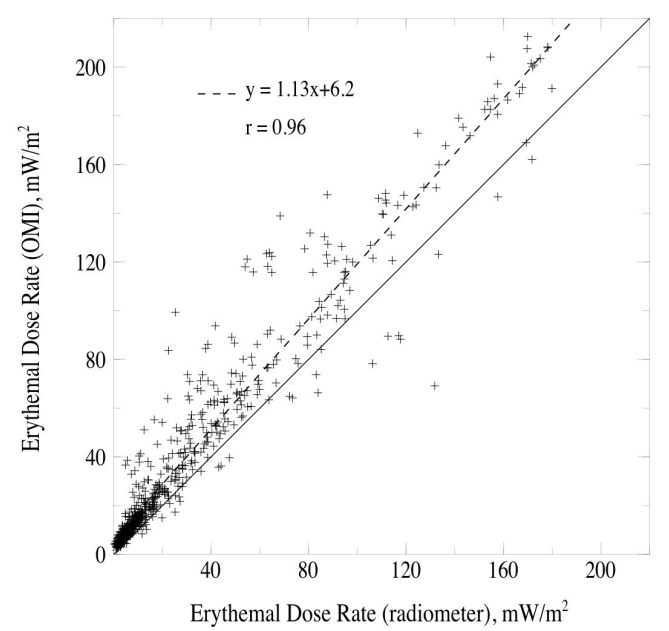

Fig. 4b. Same as Fig. 4a but for the broadband radiometer.

Finally, Fig. 5c compares the erythemal daily doses in VdA for the period October 2005-July 2006 for all sky conditions.

In $\mathrm{VdA}$, a positive bias appears $(\mathrm{OMI}>\mathrm{GB})$ as well as in Briançon when excluding snowy days, the average of relative differences is about 17\% for all sky conditions (Fig. 5d). For clear sky days (black dots), the relative differences are smaller, they do not exceed $22 \%$, but the bias remains (Fig. 5d), the average of relative differences is about $13 \%$.

As mentioned in Sect. 2.2.2, a bias is also observed in a previous validation work conducted with measurements at several sites (Tanskanen et al., 2007).

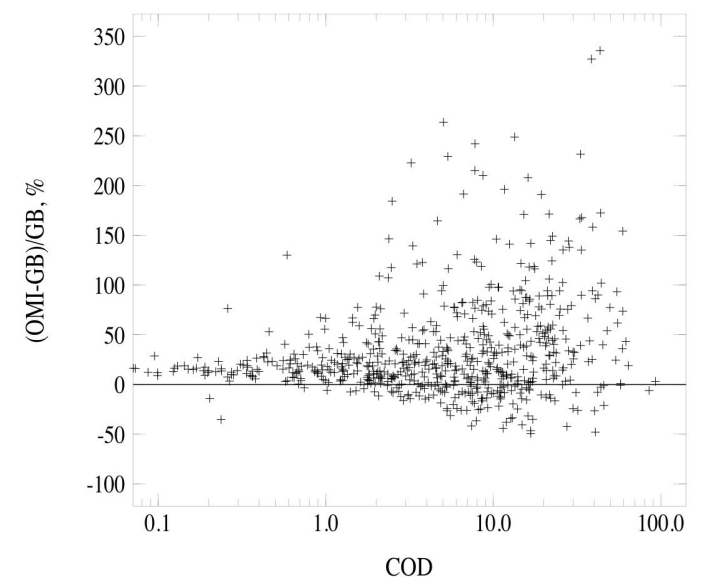

Fig. 4c. Relative differences of erythemal dose rates (OMIspectro)/spectro as a function of COD in VdA for all sky conditions.

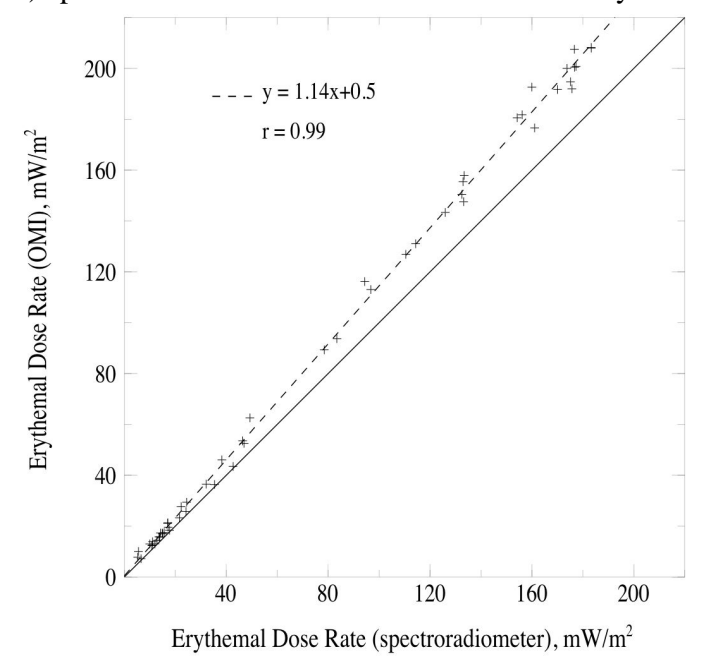

Fig. 4d. Same as Fig. 4a but for clear skies only.

\section{Summary}

The previous results from the scatter plots are summarized in Table 1 for ozone, in Table 2 for UV. For each comparison, we report the number of data pairs and in parentheses the number of points $(n)$, the correlation coefficient $(r)$, the slope and the intercept of the regression line, the RMS

$$
\left(\sqrt{\frac{1}{n} \sum_{i=1}^{n}\left(y_{i}-x_{i}\right)^{2}}\right),
$$

the \% RMS

$$
\left(\sqrt{\frac{1}{n} \sum_{i=1}^{n}\left(\frac{y_{i}-x_{i}}{x_{i}}\right)^{2}} \times 100\right)
$$

and the mean relative difference in $\%$

$$
\left(\frac{1}{n} \sum_{i=1}^{n}\left(\frac{y_{i}-x_{i}}{x_{i}}\right) \times 100\right) \text {. }
$$




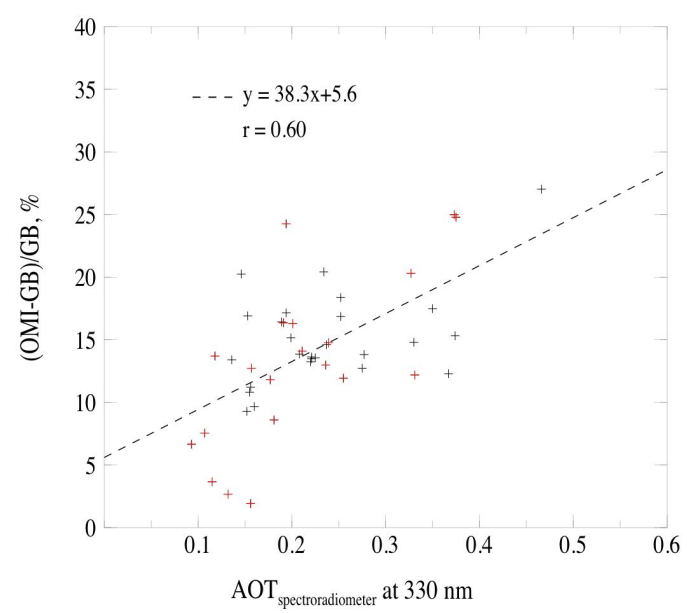

Fig. 4e. Relative differences of erythemal dose rates (OMIspectro)/spectro as a function of AOT at $330 \mathrm{~nm}$ in VdA for clear skies (red cross for $\mathrm{SZA}>65^{\circ}$ ).

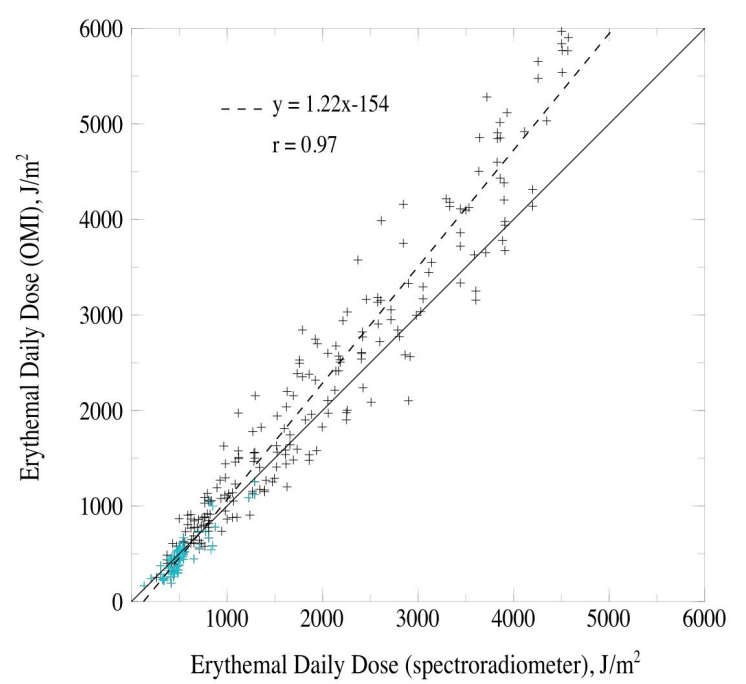

Fig. 5a. Comparison between erythemal daily doses from the spectroradiometer in Briançon and from OMI. The blue cross indicate snowy surface. The equation of the regression line (dash line) and the correlation coefficient are indicated, the solid line is the first bisector.

\section{Conclusions}

The aim of this study was to compare OMI products with measurements performed by ground-based UV instruments located at two French sites. Two spectroradiometers were used, one operating at $\mathrm{VdA}$ and the other at Briançon. The comparison of the total column of ozone shows a satisfying agreement at both sites for the OMI-TOMS-like product (the RMS are $4.1 \%$ for Briançon and $3.2 \%$ for VdA). For the OMI-DOAS-like product, the comparison conducted at $\mathrm{VdA}$ is less satisfying (RMS $=4.7 \%$ ) and a seasonal variation of the agreement appears. This phenomenon is related to a SZA effect and has been reduced in the new version of the

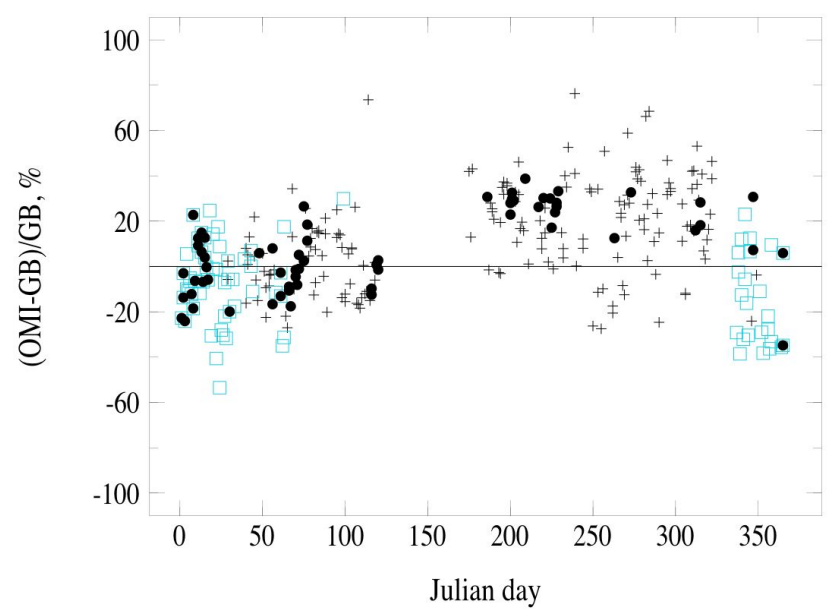

Fig. 5b. Time series of the relative differences between groundbased and OMI erythemal daily doses in Briançon (cross for cloudy day, blue squares are for snowy surface and black dots are for clear days, black dots inside blue squares are for clear snowy days).

data according to (Kroon et al., 2008) (collection 3, overpass files not yet available).

For this validation campaign a modified version of the OMI surface UV algorithm was used to provide irradiances at 324.1 and $380.1 \mathrm{~nm}$ and OMI erythemal dose rates at the time of overpass at VdA.

Spectral UV comparisons are satisfying for VdA (the mean relative differences are $6.5 \%$ and $3.7 \%$ for 324.1 and $380.1 \mathrm{~nm}$ respectively). For both wavelengths, the largest differences are observed at low irradiance level (large SZA). If we neglect the low EDR values, the comparisons of OMI erythemal dose rates for $\mathrm{VdA}$ show an overestimation of the ground-based dose rates of about $22 \%$ on average for the spectroradiometer and $34 \%$ on average for the radiometer. The same effect appears for the erythemal daily doses with an overestimation of about $17 \%$. For the site of Briançon, for most days OMI overestimates also ground-based erythemal daily doses (14\% for all sky days without snow-covered surface). If we take into account the days with snow-covered surface, the mean difference is reduced (about 8\%). These observed biases between OMI erythemal dose rates, OMI erythemal daily doses and ground-based data are in agreement with previous results obtained at other sites, including snow-covered surface cases (Tanskanen et al., 2007).

The study of the impact of the AOT on the quality of the agreement show that large AOT values can explain sometimes, large discrepancies between ground-based and satellite UV products.

The better agreement observed for spectral UV compared to the erythemal daily dose and dose rate can be explained considering that the erythemal doses concern a shorter wavelength range and that the validation of spectral irradiance at 305 and $310 \mathrm{~nm}$ is not included in the current validation work. 


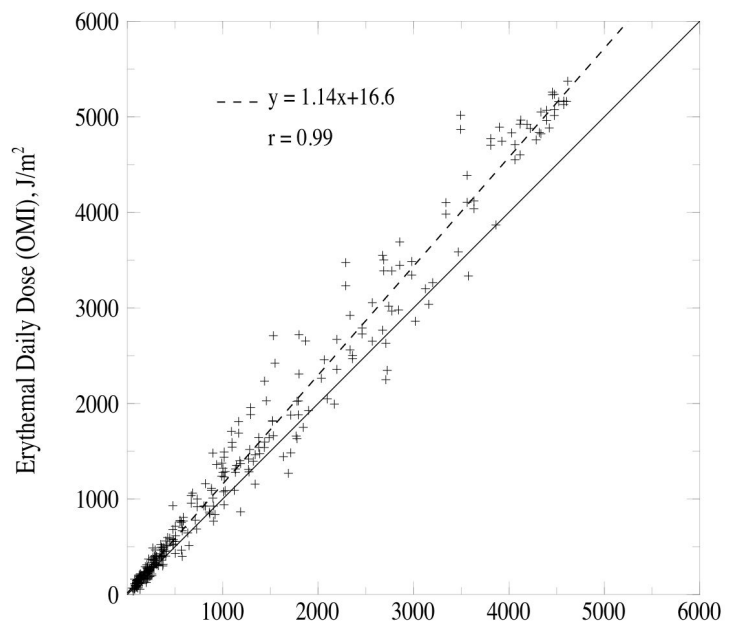

Erythemal Daily Dose (spectroradiometer), $\mathrm{J} / \mathrm{m}^{2}$

Fig. 5c. Same as Fig. 5a but in VdA.

Acknowledgements. We thank T. Cabot and A. de la Casinière for taking care of the Briançon instrument which belongs to the Centre Européen Médical et Bioclimatique de Recherche et d'Enseignement Universitaire. The sites are supported by CNES within the french program TOSCA. The figures were drawn using the Mgraph package developed at LOA by L. Gonzalez and C. Deroo (http://www-loa.univ-lille1.fr/Mgraph/). The Dutch-Finnish built OMI instrument is part of the NASA EOS Aura satellite payload. The OMI project is managed by NIVR and KNMI in the Netherlands. We thank the OMI International Science Team for the satellite data used in this study. The OMI surface UV data were obtained from the NASA Aura Validation Data Center (AVDC). This work was performed in the framework of the International ESA/KNMI/NIVR OMI "Announcement of Opportunity for Calibration and Validation of the Ozone Monitoring Instrument", providing early access to provisional OMI data sets and guidance to public OMI data. OMI overpass data is available through the Aura Validation Data Center (AVDC, http://avdc.gsfc.nasa.gov)

Edited by: J. Groebner

\section{References}

Arola, A., Kazadzis, S., Krotkov, N., Bais, A., Groebner, J., and Herman, J. R.: Assessment of TOMS UV bias due to absorbing aerosols, J. Geophys. Res., 110, D23211, doi:10.1029/2005JD005913, 2005.

Bais, A., Gardiner, B., Slaper, H., et al.: SUSPEN intercomparison of ultraviolet spectroradiometers, J. Geophys. Res., 106, D12, 12 509-12 525, 2001.

Balis, D., Kroon, M., Koukouli, M. E., Brinksma, E. J., Labow, G., Veefkind, J. P., and McPeters, R. D.: Validation of Ozone Monitoring Instrument total ozone column measurements using Brewer and Dobson spectrophotometer ground-based observations, J. Geophys. Res., 112, D24S46, doi:10.1029/2007JD008796, 2007.

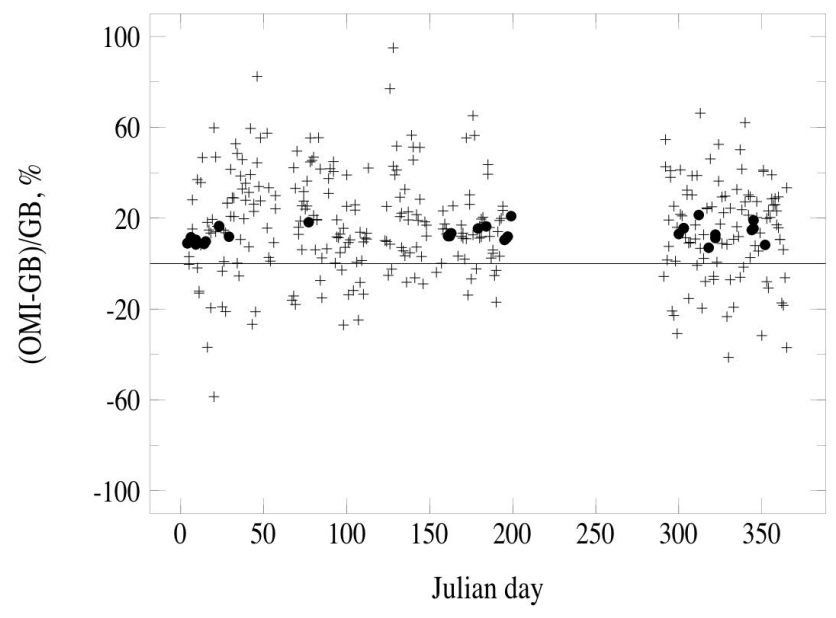

Fig. 5d. Same as Fig. $5 b$ but in VdA.

Bhartia, P. K. and Wellemeyer, C.: TOMS-V8 Total $\mathrm{O}_{3}$ algorithm, in: OMI ozone product ATBD Volume II, NASA Goddard Space Flight Center, Greenbelt, MD, USA, 2002.

Bernhard, G. and Seckmeyer, G.: Uncertainty of measurements of spectral solar UV irradiance, J. Geophys. Res., 104, 1432114345, 1999.

Brogniez, C., Houët, M., Siani, A. M., Weihs, P., Allaart, M., Lenoble, J., Cabot, T., de La Casinière, A., and Kyro, E.: Ozone column retrieval from solar UV measurements at ground level: effects of clouds and results from six European sites, J. Geophys. Res., 110, D24202, doi:10.1029/2005JD005992, 2005.

Brogniez, C., Buchard, V., and Auriol, F.: Validation of UV-visible aerosol optical thickness retrieved from spectroradiometer measurements, Atmos. Chem. Phys. Discuss., 8, 3895-3919, 2008, http://www.atmos-chem-phys-discuss.net/8/3895/2008/.

Cede, A., Luccini, E., Nuñez, L., Piacentini, R. D., Blumthaler, M., and Herman, J. R.: TOMS-derived erythemal irradiance versus measurements at the stations of the Argentine UV Monitoring Network, J. Geophys. Res., 109, D08109, doi:10.1029/2004JD004519, 2004.

Diffey, B. and McKinlay, A. F.: A reference action spectrum for ultraviolet induced erythema in human skin - human exposure to UV radiation: risks and regulations, Elsevier, NY, USA, 83-87, 1987.

Gröbner, J., Blumthaler, M., Kazadzis, S., Bais, A., Webb, A., Schreder, J., Seckmeyer, G., and Rembges, D.: Quality assurance of spectral solar UV measurements: results from $25 \mathrm{UV}$ monitoring sites in Europe 2002 to 2004, Metrologia, 43, S66S71, doi:10.1088/0026-1394/43/2/S14, 2006.

Herman, J. R., Krotkov, N., Celarier, E., Larko, D., and Labow, G.: Distribution of UV radiation at the Earth's surface from TOMSmeasured UV-backscattered radiances, J. Geophys. Res., 104, 12 059-12 076, 1999.

Houët, M. and Brogniez, C.: Ozone column retrieval from solar UV irradiance measurements at ground level: sensitivity tests and uncertainty estimation, J. Geophys. Res, 109, D15302, doi:10.1029/2004JD004703, 2004.

Kalliskota, S., Kaurola, J., Taalas, P., Herman, J. R., Celarier, E., and Krotkov, N.: Comparison of the daily UV doses estimated 
from Nimbus7/TOMS measurements and ground-based spectroradiometric data, J. Geophys. Res., 105, 5059-5067, 2000.

Kazantzidis, A., Bais, A. F., Groebner, J., Herman, J. R., Kazadizis, S., Krotkov, N., Kyro, E., den Outer, P. N., Garane, K., Gorts, P., Lakkala, K., Meleti, C., Slaper, H., Tax, R. B., Turunen, T, and Zerefos, C. S.: Comparison of satellite-derived UV irradiances with ground based measurements at four European stations, J. Geophys. Res., 111, D13207, doi:10.1029/2005JD006672, 2006.

Kroon, M., Veefkind, J. P., Sneep, M., McPeters, R. D., Bhartia, P. K., and Levelt, P. F.: Comparing OMI-TOMS and OMIDOAS total ozone column data, J. Geophys. Res., 113, D16S28, doi:10.1029/2007JD008798, 2008.

Krotkov, N. A., Bhartia, P. K., Herman, J., Ahmad, Z., and Fioletov, V.: Satellite estimation of spectral surface UV irradiance - 2: Effecct of horizontally homogeneous clouds and snow, J. Geophys. Res., 106, 11 743-11 759, 2001.

Krotkov, N. A., Herman, J., Bhartia, P. K., Seftor, C., Arola, A., Kaurola, J., Kalliskota, S., Taalas, P., and Geogdzhaev, I.: Version 2 TOMS UV algorithm: problems and enhancements, Opt. Eng., 41, 3028-3039, 2002.

Levelt, P. F., van den Oord, G. H. J., Dobber, M. R., Mälkki, A., Visser, H., de Vries, J., Stammes, P., Lundell, J. O. V., Saari, H.: The Ozone Monitoring Instrument, IEEE T. Geosci. Remote, 44(5), 1093-1101, 2006a.

Levelt, P. F., Hilsenrath, E., Leppelmeier, G. W., van den Oord, G. B. J., Bhartia, P. K., Tamminen, J.: Science objectives of the ozone monitoring instrument, IEEE T. Geosci. Remote, 44(5), 1199-1208, 2006b.

McKenzie, R. L., Seckmeyer, G., Bais, A. F., Kerr, J. B., and Madronich, S.: Satellite retrievals of erythemal UV dose compared with ground-based measurements at northern and southern midlatitudes, J. Geophys. Res., 106, 24 051-24 062, doi:10.1029/2001JD000545, 2001.

Paur, R. J. and Bass, A. M.: The ultraviolet cross sections of ozone2: Results and temperature dependence, in: Atmospheric Ozone, Proceedings of the Quadriennal Ozone Symposium, Haldikiki, Greece, 3-7 September 1984, 611-616, 1985.
Slaper, H., Reinen, H., Blumthaler, M., Huber, M., and Kuik, F.: Comparing ground-level spectrally resolved solar UV measurements using various instruments: a technique resolving effects of wavelength shift and slit width, Geophys. Res. Lett., 22(20), 2721-2724, 1995.

Stamnes, K., Tsay, S. C., Wiscombe, W. J., and Jayaweera, K.: Numerically stable algorithm for discrete ordinate method radiative transfer in multiple scattering and emiting layered media, Appl. Opt., 27, 2502-2509, 1988.

Stamnes, K., Slusser, J. R, and Bowen, M.: Derivation of total ozone abundance and cloud effects from spectral irradiance measurements, Appl. Opt., 30, 4418-4426, 1991.

Tanskanen, A.: Lambertian surface albedo climatology at $360 \mathrm{~nm}$ from TOMS data using moving time-window technique, in "Proceedings of the 20th Quadriennal Ozone Symposium", Kos, Greece, 1-8 June 2004, 1159-1160, 2004.

Tanskanen, A., Krotkov, N. A., Herman, J. R., and Arola, A.: Surface Ultraviolet Irradiance from OMI, IEEE T. Geosci. Remote, 44(5), 1267-1271, 2006.

Tanskanen, A., Lindfors, A., Määttä, A., Krotkov, N., Herman, J., Kaurola, J., Koskela, T., Lakkala, K., Fioletov, V., Bernhard G., McKenzie, R., Kondo, Y., O’Neill, M., Slaper, H., den Outer, P., Bais, A., and Tamminen J.: Validation of daily erythemal doses from ozone monitoring Instrument with groundbased UV measurement data, J. Geophys. Res., 112, D24S44, doi:10.1029/2007JD008830 2007.

Veefkind, J. P., de Haan, J. F., Brinksma, E. J., Kroon, M., and Levelt, P. F.: Total ozone from the ozone monitoring instrument (OMI) using the DOAS technique, IEEE T. Geosci. Remote, 44(5), 1239-1244, 2006.

WMO: Scientific assessment of ozone depletion 2006, WMO Report No.50, World Meteorological Organization, Geneva, Switzerland, 2007. 